This is the peer reviewed version of the following article: Raja, Usman, Haq, Inam Ul, De Clercq, Dirk and Azeem, Muhammad Umer (2020) When ethics create misfit : combined effects of despotic leadership and Islamic work ethic on job performance, job satisfaction, and psychological well-being. International Journal of Psychology, 55(3), pp. 332-341., which has been published in final form at https://doi.org/10.1002/ijop.12606. This article may be used for non-commercial purposes in accordance with Wiley Terms and Conditions for Use of Self-Archived Versions. 
When Ethics Create Misfit: Combined Effects of Despotic Leadership and Islamic Work Ethic on Job Performance, Job Satisfaction, and Psychological Well-Being

\author{
Usman Raja \\ Inam Ul Haq \\ Dirk De Clercq \\ Muhammad Umer Azeem
}

Paper accepted for publication in International Journal of Psychology 


\title{
When Ethics Create Misfit: Combined Effects of Despotic Leadership and Islamic Work Ethic on Job Performance, Job Satisfaction, and Psychological Well-Being
}

\begin{abstract}
This study applies social exchange and person-environment fit theories to predict that despotic leaders tend to hinder employee job performance, job satisfaction, and psychological well-being, whereas employees' own Islamic work ethic (IWE) enhances these outcomes. A strong IWE also can moderate the relationship of despotic leadership with the three outcomes, such that it heightens the negative impacts, because employees with a strong IWE find despotic leadership particularly troubling. A multi-source, two-wave, time-lagged study design, featuring a diverse sample (303 paired responses) of employees working in various organizations, largely supports these predictions. Despotic leadership and IWE relate significantly to job performance, job satisfaction, and psychological well-being in the predicted directions, except that there is no significant relationship between IWE and job satisfaction. A test of moderation shows that the negative relationships of despotic leadership with job outcomes is stronger when IWE is high. These findings have pertinent implications for theory, as well as for organizational practice.
\end{abstract}

Keywords: despotic leadership, Islamic work ethic, social exchange theory, person-environment fit 
The substantial research that addresses leadership in organizations primarily focuses on positive aspects rather than unethical or dysfunctional leader behaviours (Andersson \& Pearson, 1999; Schilling, 2009). An implicit assumption in this research is that ineffective leadership is equivalent to a lack of leadership, but increasing insights into the dark side of destructive leadership in organizations contest this assumption (e.g., Naseer, Raja, Syed, \& Donia, 2016). Destructive leadership is not simply the absence of effective leadership qualities; rather, it implies behaviours that harm followers, including corruption, information distortion, manipulation, and illegal or criminal acts (Schyns \& Hansbrough, 2010). Such harmful leadership behaviours can be described with various labels, such as petty tyranny, abusive supervision, or despotic leadership (Naseer et al., 2016). Noting that negative leadership behaviours harm not just subordinates but also the organization or even customers, Einarsen, Aasland, and Skogstad (2007, p. 208) define destructive leadership as "the systematic and repeated behavior by a leader, supervisor or manager that violates the legitimate interest of the organization by undermining and/or sabotaging the organization's goals, tasks, resources, and effectiveness and/or the motivation, well-being or job satisfaction of subordinates."

Among the various types of negative leadership (Schilling, 2009), despotic leadership in particular has been insufficiently explored (Naseer et al., 2016). A despotic leader engages in authoritarian, dominating behaviours to achieve his or her self-interests, as well as selfaggrandizing and exploitation of subordinates (Aronson, 2001). Such leaders are tyrannical and arrogant, and they adopt unethical codes of conduct. Because of their potential to harm individual well-being and performance, which directly determines organizational performance (De Hoogh \& Den Hartog, 2008; Naseer et al., 2016), despotic leaders require further research attention. In particular, we need insights into how it functions for organizations in developing 
countries, especially those marked by high power distance and collectivism but limited alternative employment opportunities (Hofstede, 2007). These conditions create a context that is very different from the organizational setting that dominates most developed, Western countries, where most leadership research has been conducted (Naseer et al., 2016). That is, we need to test how various concepts promulgated in developed countries, including the effects of leadership, are manifest in developing countries.

To address these gaps, we explore the harmful effects of despotic leadership on employees' performance, satisfaction, and well-being in Pakistan. Despotic leadership may be especially relevant and contextually pertinent for cultures that tend to be collectivistic, communal, and marked by high power distance (Hofstede, 2007), because the resulting contexts seemingly allow leaders to engage in selfish, abusive, and tyrannical behaviours. In addition to responding to calls to study the consequences of negative leader behaviours in developing countries (Naseer et al., 2016), we offer new insights into factors that might exacerbate these negative leadership effects. Pakistan is a largely Islamic nation, and we posit that an Islamic work ethic (IWE) — defined as the extent to which employees embrace Islamic ethical values in their daily work activities (Ali, 1992; De Clercq, Rahman, \& Haq, 2017)—might exert both direct effects on employee outcomes (performance, satisfaction, and well-being) and invigorating influences on the links between despotic leadership and these outcomes. An IWE overlaps closely with the Protestant work ethic (PWE), which is more familiar in Western cultures (Zulfikar, 2012). According to Ali (1988), an IWE calls for hard work and finding a balance between work and personal lives. Furthermore, IWE and PWE align in many ways, in that workrelated values are similar across religions, especially Judaism, Christianity, and Islam (Ntalianis 
\& Raja, 2000). Similar to the PWE, a work ethic rooted in Islam emphasizes diligence, honesty, fairness, and altruism (Ali, 1992).

By focusing on the IWE though, we extend prior research that tends to prioritize a Western perspective. Global corporations hire many Muslim employees and are investing in countries with largely Muslim populations. Therefore, it is critical to explore factors that might influence the work-related behaviours of employees of Islamic faith. Recent research offers some support that an IWE exerts notable influences in work settings. For example, Khan, Abbas, Gul, and Raja (2015) identify IWE as a moderator of the relationship between justice types and job outcomes, then call for further research to examine its moderating effects on other work-related outcomes. De Clercq et al. (2017) similarly find a moderating role of IWE in the relationship between family-work conflict and helping behaviours.

To define these effects, we anchor our theoretical arguments in social exchange theory (Blau, 1964; Emerson, 1976) and person-environment (PE) fit theory (Chatman, 1989; Kristof, 1996). Social exchange theory suggests that in most social exchanges, exchange partners respond in ways that mimic how they have been treated previously by the other partner (Blau, 1964). Employees who find themselves in social exchange relationships with selfish, tyrannical leaders tend to experience their work situation as negative and thus might seek to retaliate (Naseer et al., 2016). In addition, PE fit theory underscores the importance of matching employees' individual values with the surrounding organizational environment, because such fit can generate positive attitudes and behaviours (Boon \& Biron, 2016), which are less likely in the presence of despotic leadership (De Hoogh \& Den Hartog, 2008).

Taken together, we seek to contribute to extant research by investigating the unexplored, combined, and interactive effects of despotic leadership and IWE on three critical individual 
outcomes: job performance, job satisfaction, and psychological well-being. Employees who work for a despotic leader may be so frustrated with the quality of the exchange relationship and experience such poor PE fit (De Hoogh \& Den Hartog, 2008) that any positive work outcomes become thwarted. Further, if employees score high on IWE, they tend to prioritize hard work, dedication, honesty, and loyalty, and these features could spur their search for better goal alignment with their organization (Khan et al., 2015). In this case, the resulting PE fit should invoke higher job performance, job satisfaction, and psychological well-being. However, when these two factors combine-employees with a strong IWE are exposed to a despotic leader whose behaviours conflict with the principles underlying their work ethic-employees might experience this leadership style as particularly upsetting, such that an IWE exacerbates the negative impact of despotic leadership on positive outcomes. To test these predictions, we gather data from 303 employee-supervisor pairs, spanning a range of organizations in the understudied context of Pakistan. With a two-wave, time-lagged research design, this study accordingly provides novel insights into the work-related effects of a dark side of leadership in a developing nation.

\section{Hypotheses}

\section{Despotic Leadership and Employee Outcomes}

A despot uses her or his power cruelly and oppressively; a despotic leader holds significant power and acts like a tyrant or dictator, using the vast power arbitrarily, unjustly, and mercilessly (Aronson, 2001). Despotic leaders behave callously and for their own self-interest, with no concern for others' needs (Schilling, 2009). They often act in conflict with the legitimate interests of the organization and rarely involve subordinates in decision making (Aronson, 2001). Despotic leaders also exhibit unethical and unfair behaviours (De Hoogh \& Hartog, 2008), such 
that their subordinates tend to feel less happy about the work situation and are less productive (Naseer et al., 2016). Both social exchange theory and PE fit theory predict that employees' exposure to such despotic leadership should have harmful effects on three key outcomes: job performance, job satisfaction, and psychological well-being.

First, according to social exchange theory (Blau, 1964), any social exchange consists of a give-and-take sequence, in which the parties to the exchange respond according to how the other party has treated them previously (Emerson, 1976; Naseer et al., 2016). If a leader indulges in evil deeds, the employee as a recipient of that treatment likely reacts negatively, such as by reducing efforts to achieve strong performance (Kelley, 1968; Naseer et al., 2016). That is, a leader who treats subordinates with disdain creates negatives exchanges, to which employees might respond by withholding productive work behaviours (Blau, 1964). This negative quid pro quo also may produce a negative environment that undermines employees' overall job satisfaction and psychological well-being. That is, despotic leaders, whose ethical character is questionable, tend to generate negative emotions in employees and undermine their overall happiness with their job and life (Kanungo, 2001; Naseer et al., 2016).

Second, according to PE fit theory (Kristof, 1996), a poor fit between employees and their work environment hinders their job attitudes and behaviours (Boon \& Biron, 2016). If they perceive the organizational environment as unfair or disrespectful, they also sense a low level of fit, which results in undesired outcomes (Chatman, 1989). For example, unethical treatment, excessive control, and perceived injustice can create poor PE fit, which then may escalate into a reduced willingness to contribute to organizational effectiveness, as well as negative perceptions of the job situation (Boon \& Biron, 2016). Similarly, people working under a despotic leader are exposed to an unpleasant organizational environment, marred by intimidation or unjust, abusive 
tactics (De Hoogh \& Den Hartog, 2008; Naseer et al., 2016). The resulting poor PE fit accordingly should diminish the performance, satisfaction, and well-being of employees. Therefore:

Hypothesis 1: Employees' exposure to despotic leadership relates negatively to their job performance, job satisfaction, and psychological well-being.

\section{Islamic Work Ethic and Employee Outcomes}

An IWE stems from values rooted in the Islamic faith. Observant Muslims evaluate all their actions according to Islamic tenets, values, and ethics (Khan et al., 2015), and this comprehensive religious system details how adherents should conduct their daily economic and social activities (Beekun, 1997). Work diligence, dedication, and loyalty are religious responsibilities, in that Muslims believe that "Hard work absolves the sins of people and the best food which a person eats is that which he eats out of his work" (Khan et al., 2015, p. 238). Islam also strictly forbids unproductive behaviours, such as laziness or wasting time (Ali \& Gibbs, 1998). Moreover, the workplace is a place for cooperation and dedication, where employees can find satisfaction and self-fulfilment (De Clercq et al., 2017). Many studies cite positive effects of an IWE on performance, knowledge sharing, citizenship behaviours, and satisfaction. Khan et al. (2015) show that an IWE relates positively to job satisfaction and job involvement but negatively to turnover intentions; Murtaza et al. (2016) find positive relationships of IWE with both organizational citizenship and knowledge sharing behaviours.

We similarly expect a positive relationship between employees' IWE and their job performance, job satisfaction, and psychological well-being. An IWE covers a broad range of values with direct impacts on how employees behave at work (Khan et al., 2015; Murtaza et al., 2016). Employees with a strong IWE likely achieve better performance, because they put in more effort to fulfil their duties, which they perceive as a religious obligation, regardless of the 
context (De Clercq et al., 2017). Because people with a strong IWE consider it their obligation to work hard and also experience personal fulfilment from these efforts, they also tend to be more satisfied in their jobs (Khan et al., 2015). Finally, employees marked by a high IWE tend to have a strong religious faith, which might enhance their overall psychological well-being (Ali, 1992). Consistent with the PE fit perspective (Kristof, 1996), we anticipate that people with a strong IWE embrace values that align with the goals of their employer; their propensity to value hard work, loyalty, and honesty should create a good fit with the work environment, which helps them perform better, feel more satisfied, and exhibit more psychological well-being. Formally,

Hypothesis 2: Employees' IWE relates positively to their job performance, job satisfaction, and psychological well-being.

\section{Islamic Work Ethic as a Moderator}

Employees' IWE also might invigorate the negative relationship between employees' exposure to despotic leadership and their job performance, job satisfaction, and psychological well-being. An IWE reflects moral values rooted in Islam, which distinguish what is right from what is wrong (Beekun, 1997). As mentioned, an employee with a strong IWE perceives the workplace as a place for cooperation, dedication, and hard work (Ali, 1992) and emphasizes her or his positive contributions to a friendly workplace environment in which she or he fulfils required job responsibilities (Khan et al., 2015). With their clear sense of right and wrong, these employees tend to adhere to strong ethical and moral principles. The invigorating effect of IWE thus resonates with the premises of social exchange theory (Blau, 1964), because employees with a stronger IWE should feel particularly frustrated by low-quality exchange relationships with organizational leaders (Ali, 1992) and respond more negatively to despotic leadership, with diminished performance, job satisfaction, and psychological well-being. 
The invigorating effect of IWE also is consistent with PE fit theory (Boon \& Biron, 2016; Kristof, 1996). Employees with a strong IWE should be particularly sensitive to and upset by the manipulative and intimidating behaviours of despotic leaders, who follow unethical practices, exhibit unethical codes of conduct, and treat subordinates unfairly (De Hoogh \& Hartog, 2008). These unethical, socially unconstructive methods, and the toxic work environment that they create (Aronson, 2001; Naseer et al., 2016), should prompt a strong sense of PE misfit among employees who score high on IWE, leading to an exacerbated effect of the undesired outcomes of despotic leadership, namely, even worse performance, lower job satisfaction, and diminished psychological well-being. Because employees with a strong IWE embrace values that directly contradict the tactics of despotic leaders, they likely perceive that they are working in a context that does not align with their value system, which enhances the negative impact of their exposure to despotic leadership. Formally:

Hypothesis 3: Employees' IWE moderates the negative relationships between their exposure to despotic leadership and (a) job performance, (b) job satisfaction, and (c) psychological well-being, such that the relationship is stronger when IWE is high.

\section{Method}

\section{Data Collection}

To capture enough variance in despotic leadership, we collected data from employees working at various organizations in Lahore, the second largest city in Pakistan. Specifically, the organizations included multiple branches of high schools, two branches of a well-known bank, and an engineering firm. To avoid issues associated with cross-sectional designs (e.g., method bias), we used a time-lagged design, such that we measured despotic leadership at time 1 (T1), then measured IWE, job performance, job satisfaction, and psychological well-being at time 2 (T2). To mitigate self-reporting bias, we obtained supervisor reports of the employees' job 
performance at T2. A cover letter outlined the objectives of the research for all respondents, assured them of strict confidentiality, and explained that their participation was voluntary, such that they could refuse to participate in any stage.

At T1, we distributed 550 questionnaires and received 450 completed surveys back, for a response rate of $81 \%$. One month later, we contacted these 450 respondents and requested that they complete another short survey. Of the 450 questionnaires sent out at T2, we received 324 completed surveys, for a response rate of $72 \%$. At T2, we also contacted the supervisors of the 450 participants that had responded at $\mathrm{T} 1$ and provided them with a very short survey about the performance of their subordinates. We received 310 completed performance ratings (response rate $=69 \%$ ). By matching the respondents (303) with supervisors (43), we obtained a final sample of 303 paired data. Among the 303 participating employees, 236 worked for a high school, 18 for a bank, and 49 for the engineering firm.

Because 43 supervisors assessed 303 employees - and 34 supervisors assessed more than one employee - our data structure is nested, so we checked whether it was useful to apply hierarchical linear modelling (HLM) to test the hypotheses. With the supervisor as a grouping variable, we ran the null model in HLM to calculate between- and within-group variances for supervisor-rated job performance. Following Abbas, Raja, Darr, and Bouckenooghe (2014), we assessed whether it was desirable to run complex models that control for data nesting, using the supervisor as the higher-order level variable. The between-supervisor variance explained only $8 \%$ of the total variance in job performance, which is a very small effect size (Cohen, 1988). In contrast, $24 \%$ of the total variance in job performance can be attributed to within-supervisor variance. The F-statistic for the ratio of the two variances also is not significant, $\mathrm{F}(42,260)=$ 
$.25, n s$. Therefore, using the supervisor as a grouping variable does not explain enough variance to justify the application of HLM (Bryk \& Raudenbush, 1992).

In terms of demographics, $58 \%$ of the employee respondents are women, the mean age is 29.54 years $(\mathrm{SD}=6.97)$, and about $40 \%$ of respondents had five or more years of work experience. Their occupational levels ranged from blue collar workers (31) and junior clerical staff (21) to mid-level management and supervisory positions (245), to senior management (6); the majority thus held at least mid-level positions. A one-way analysis of variance to check for significant differences in the dependent variables across gender and organization confirmed such variations, so we controlled for gender and organization, using dummy variables, in the regression analysis (one dummy variable for gender, two dummy variables for the three organization types).

\section{Measures}

The construct measures used self-reported instruments, except for job performance, for which we relied on supervisory ratings. The responses on 5-point Likert-type scales ranged from $1=$ strongly disagree to $5=$ strongly agree. We used the original, English versions of all question items, which was justifiable, because all respondents were working in jobs that required at least a high school diploma, if not a bachelor's degree from a university. English is the language used for all high school and university education in Pakistan, as well as for official communication at work. Thus for this sample, we did not need to translate the survey items, and we did not receive any complaints or questions about language difficulties.

Despotic Leadership. We used a 6-item scale by De Hoogh and Den Hartog (2008) to measure despotic leadership at T1. Sample items included, "My supervisor has no pity or 
compassion" and "My supervisor is in charge and does not tolerate disagreement or questioning." The alpha reliability of this scale was .81 .

Islamic Work Ethic. For IWE, we relied on the 17-item scale of Ali (1992), measured at T2. The measure prompted respondents, "Please answer the following questions in light of your religious beliefs. As a Muslim, how much you agree or disagree with the following statements?" Sample items included "Laziness is a vice" and "Dedication to work is a virtue." The reliability for this scale was .86 .

Job Performance. At T2, the supervisors rated their subordinates' job performance on a 7-item scale developed by Williams and Anderson (1991), including for example, "This employee adequately completes assigned duties" and "This employee performs tasks that are expected of him/her." The reliability was .88 .

Job Satisfaction. We measured job satisfaction at T2 with a 6-item scale developed by Schriesheim and Tsui (1980). Sample items were "I am satisfied with the nature of the work I perform" and "I am satisfied with the pay I receive for my job," and the scale reliability reached .86.

Psychological Well-Being. At T2, we measured psychological well-being with 8 items from the flourishing scale developed by Diener et al. (2009). Sample items included "I lead a purposeful and meaningful life" and "I am engaged and interested in my daily activities," and the reliability for this scale was .90 .

\section{Results}

Table 1 contains the descriptive statistics, correlations, and reliabilities, and Table 2 provides the multiple moderated regression results. We entered the dummy variables for gender and organization type in the first step, followed by the 
independent variable and moderator in a second step. Finally, the third step included the despotic leadership $\times$ IWE interaction. We centred all predictors for the moderated regression. According to the Step 2 results in Table 2, despotic leadership relates negatively to employees' job performance $(\beta=-.36, p<.001)$, job satisfaction $(\beta=-.20, p<.001)$, and psychological wellbeing $(\beta=-.18, p<.01)$, in full support of Hypothesis 1 . Furthermore, IWE relates positively to job performance $(\beta=.35, p<.001)$ and psychological well-being $(\beta=.20, p<.01)$, though its relationship with job satisfaction is not significant $(\beta=.07, n s)$, so we find partial support for Hypothesis 2.

Insert Tables 1 and 2 about here

The Step 3 results in Table 2 reveal that the product term despotic leadership $\times$ IWE relates significantly to job performance $(\beta=-.15, p<.01)$, job satisfaction $(\beta=-.18, p<.01)$, and psychological well-being $(\beta=-.23, p<.001)$. We conducted simple slope tests and plotted the corresponding interaction graphs at low and high (Mean $\pm 1 \mathrm{SD}$ ) values of the moderator. First, Figure 1 presents the interaction graph for the despotic leadership-job performance relationship; the simple slope test indicates that despotic leadership relates strongly and negatively to job performance when IWE is high $(\beta=-.49, p<.001)$ but not significantly when IWE is low $(\beta=-.09, n s)$. These findings support Hypothesis 3a, in that the negative relationship between despotic leadership and job performance is stronger at high IWE. Second, the interaction graph for the despotic leadership-job satisfaction relationship in Figure 2 suggests a negative, significant relationship at high $\operatorname{IWE}(\beta=-.33, p<.001)$ and a marginally significant, positive relationship at low IWE $(\beta=.18, p<.10)$. In support of Hypothesis $3 b$, the negative relationship between despotic leadership and job satisfaction grows stronger at higher levels of 
IWE. Yet these results also reveal a stronger effect than we predicted, which was not just weaker but even became positive at low levels of IWE. Third, Figure 3, depicting the results of the simple slope test for despotic leadership and psychological well-being, reveals a strongly negative relationship at high IWE $(\beta=-.61 p<.001)$ but a positive one at low IWE $(\beta=.31, p<$ $.05)$. These findings again are even stronger than we predicted, because the despotic leadershippsychological well-being relationship is positive, not just weaker, when IWE is low instead of high. Overall, these results support Hypothesis 3c.

Insert Figures 1-3 about here

\section{Discussion}

The dark side of leadership is an important research topic, especially in light of corporate scandals such as those at WorldCom and Enron (Naseer et al., 2016). Despotic leadership warrants consideration in particular, due to its strong potential to exert detrimental effects on both personal and organizational outcomes (De Hoogh \& Den Hartog, 2008; Naseer et al., 2016). We further predict that these effects should be especially salient to people who have a strong IWE, which orients them to be honest and hardworking. The study of despotic leadership also is particularly relevant in contexts where power distance is high and economic development is low—contexts that provide ideal conditions for a despot to enforce his or her selfish and aggressive agenda on followers (Naseer et. al., 2016). Pakistan represents such a country context. Moreover, more than $90 \%$ of the Pakistani population is Muslim (Khan et al., 2015), which provides a context well suited to study the combined effects of despotic leadership and IWE.

Our empirical results largely support the theoretical arguments, anchored in social exchange theory and PE fit theory. First, despotic leadership exerted the predicted negative effects on all three job outcomes (job performance, job satisfaction, and psychological well- 
being), and IWE related positively to two of the three criterion variables (job performance and psychological well-being). We also found support for the interaction hypotheses, in that IWE enhanced the negative effects of despotic leadership on performance, satisfaction, and wellbeing. These interactive effects of despotic leadership and IWE suggest that unethical practices and unfair treatment by leaders are particularly likely to translate into poorer job outcomes among employees with a stronger IWE.

The focus of this research on the invigorating role of IWE in channelling employees' perceptions of despotic leadership into negative work outcomes offers organizational decision makers with expanded insights into the personal conditions in which the frustration that comes with arrogant and demeaning leader behaviours exacerbates these outcomes. In particular, the possession of Islamic work values functions as a catalyst, enhancing the extent to which employees suffer from and respond negatively to destructive leader behaviours. With this interesting and somewhat counterintuitive insight, this study complements previous research on the direct effects of IWE on positive work behaviours (De Clercq et al., 2017) and professional and private well-being (Yousef, 2000). Moreover, by affirming the theorized invigorating effects, we extend extant research that has centred on the buffering roles of IWE in mitigating the negative consequences of adverse work conditions, such as family-to-work conflict (De Clercq et al., 2017) or perceptions of organizational politics (Rawwas, Javed, \& Iqbal, 2018). Even if Islamic work values can instil positive energy in employees, which they might use to cope with workplace challenges, this effect is seemingly overshadowed by their expectations about how they should be treated by leaders (Ali, 1992; Boon \& Biron, 2016). Thus, the presence of destructive leadership, in the form of despotism, leads to lower job performance, job 
satisfaction, and personal well-being more forcefully to the extent that employees' personal beliefs make disrespectful leader treatments unacceptable to them.

A notable result from our investigation pertains to the cross-over interaction when despotic leadership combines with a strong IWE to influence the specific outcomes of job satisfaction and psychological well-being. That is, we predicted that employees with a weaker IWE would be less upset by the misfit between their despotic leaders' behaviours and their personal work ethic, such that the effects on the studied outcomes would be weaker. Instead, we find that the relationships of despotic leadership with job satisfaction and psychological wellbeing switch in sign and become positive when employees express a weak IWE. A possible explanation for this finding is that employees with a weak IWE might feel less threatened by and more accepting of the behaviours that their despotic leader pursues, even if they do not formally approve of these behaviours. Moreover, employees with a low IWE score may hold ethical values that are more self-centred, such that they perceive adequate fit when working for a leader who exhibits similar self-serving tendencies. However, this highly speculative, post hoc explanation demands caution and further investigation in qualitative studies. Notably, we do not find a cross-over interaction effect for job performance as a behavioural outcome. Perhaps employees who score low on IWE are more accepting of despotic tendencies by their leaders, but this acceptance does not eliminate the threat to their performance efforts.

\section{Practical Implications}

These findings have several implications for both managers and organizations. Leaders must re-examine their despotic attitudes and behaviours, and organizational decision makers should implement policies to detect and minimize despotic tendencies among potential leaders, including gathering regular feedback from subordinates and peers. Organizational designs should 
explicitly aim to keep the tyrannical tendencies of their leaders in check, such as by encouraging employees to raise complaints related to bullying, aggression, intimidation, or harassment—all of which might indicate despotic tendencies. Our results also suggest that nurturing and harnessing IWE among employees can be beneficial for organizations that operate in an Islamic context, because this work ethic leads to improved job performance, job satisfaction, and psychological well-being. Organizations that operate in Islamic countries might adopt codes of conduct based in Islam, along with training programs tailored to encourage an IWE. Furthermore, organizations could pursue corporate-level ethics that align with the extent to which an IWE is important to employees.

In addition, this study is particularly insightful in its finding that organizations should avoid situations in which leaders exhibit despotic behaviours toward followers who hold a strong IWE, because this combination can generate a negative spiral of diminished job performance, job satisfaction, and psychological well-being. Organizations whose employees score high on IWE can benefit particularly from implementing mechanisms that limit despotic tendencies among leaders. Facilitating confidential feedback or appointing an ombudsman, for example, might help solidify organizational efforts to monitor leaders' disrespectful or unethical practices; ignoring such unethical practices is very risky, to the extent that they stand in stark contrast with the ethical values maintained by the firm's employee base.

\section{Strengths, Limitations, and Further Research Directions}

Our study offers several insights for research. First, we used a time-lagged (two-wave) design, such that we tapped the independent variable at one time, then the moderator and personal outcome variables a month later. Although the design is not purely longitudinal, this approach reduces problems associated with method bias and cross-sectional designs, by 
separating the measures of the suggested causes and effects. Second, we used supervisor reports to measure job performance, which reduces concerns about reporting bias and ensures the independence of the criterion variable. Third, this research applied management theories and concepts conceived of in developed, Western settings to a developing, non-Western context. Such efforts are important and should continue; many developing countries (e.g., Pakistan, India, China) host vastly growing economies with huge populations, and their cultures differ notably from typical Western cultures (Hofstede, 2007). For example, Eastern cultures tend to feature high power distance, collectivism, and risk aversion, so they are highly relevant for studies that address concepts such as despotic leadership (Naseer et al., 2016).

Despite these strengths, our study also has some limitations, which suggest avenues for further research. First, to extend our consideration of the impact of despotic leadership on job outcomes, additional research might address other destructive leadership styles too, such as abusive supervision, derailed leadership, or tyrannical leadership, as well as their unique relationships with IWE (Schilling, 2009). Second, we only considered one type of work ethic (IWE), so we could not test its potential value relative to other ethical types, whether religiously based (e.g., PWE) or otherwise. Comparisons across countries, religions, and work settings could help address this concern. It also would be interesting to determine if the effects of IWE hold after researchers control for personality aspects, such as altruism or duty orientation. Third, our IWE measure may not have captured the overall concept of an Islamic work ethic in its complex entirety. The measure we used (Ali, 1992) is the best established version (e.g., De Clercq et al., 2017; Khan et al., 2015; Murtaza et al., 2016), but more elaborate measures of IWE could be developed and tested. Fourth, as noted, we used a two-wave, time-lagged design, but it is not a pure longitudinal study that measured changes in the outcome measures at different points in 
time. Finally, studies that adopt longer time frames could explicitly measure and assess the explanatory mechanisms that underpin the hypothesized relationships, such as the perceived misfit between leaders' practices and personal values or desires to reciprocate disrespectful leader behaviours.

In conclusion, this study shows that despotic leadership is detrimental to employee job performance, job satisfaction, and psychological well-being, and these effects are enhanced when employees have a strong IWE. Using these findings as a basis, further research could derive more complex, elaborate models that include the effects of different leadership styles and ethical value systems on various work outcomes. Organizations also can use our results as catalysts to establish work environments that discourage despotic tendencies among their current or aspiring leaders, as well as to identify which employees might be most sensitive to dysfunctional leader treatment. 


\section{References}

Abbas, M., Raja, U., Darr, W., \& Bouckenooghe, D. (2014). Combined effects of perceived politics and psychological capital on job satisfaction, turnover intentions, and performance. Journal of Management, 40, 1813-1830.

Ali, A. (1988). Scaling an Islamic work ethic. Journal of Social Psychology, 128, 575-583.

Ali, A. J. (1992). The Islamic work ethic in Arabia. Journal of Psychology, 126, 507-519.

Ali, A. J., \& Gibbs, M. (1998). Foundations of business ethics in contemporary religious thought: The ten commandment perspective. International Journal of Social Economics, $25,1552-1564$.

Andersson, L., \& Pearson, C. (1999) Tit for tat? The spiraling effect of incivility in the workplace. Academy of Management Review, 24, 452-471.

Aronson, E. (2001). Integrating leadership styles and ethical perspectives. Canadian Journal of Administrative Sciences, 18, 244-256.

Beekun, R. (1997). Islamic Business Ethics. IIIT, Herndon, Virginia, U.S.A.

Blau, P.M. (1964). Exchange and power in social life. New York: Wiley.

Boon, C., \& Biron, M. (2016). Temporal issues in person-organization fit, person-job fit and turnover: The role of leader-member exchange. Human Relations, 69, 2177-2200.

Bryk, A. S., \& Raudenbush, S. W. (1992). Advanced qualitative techniques in the social sciences, 1. Hierarchical linear models: Applications and data analysis methods. Thousand Oaks, CA: Sage Publications.

Chatman, J. A. (1989). Improving interactional organizational research: A model of personorganization fit. Academy of Management Review, 14, 333-349. 
Cohen, J. (1988). Statistical power analysis for the behavioral sciences ( $2^{\text {nd }}$ ed.). Hillsdale, NJ: Lawrence Erlbaum Associates.

De Clercq, D., Rahman, Z., \& Haq, I.U. (2017). Explaining helping behavior in the workplace: The interactive effect of family-to-work conflict and Islamic work ethic. Journal of Business Ethics, doi:10.1007/s10551-017-3541-3.

De Hoogh, A. H., \& Den Hartog, D. N. (2008). Ethical and despotic leadership, relationships with leader's social responsibility, top management team effectiveness and subordinates' optimism: A multi-method study. Leadership Quarterly, 19, 297-311.

Diener, E., Wirtz, D., Tov, W., Kim-Prieto, C., Choi, D. W., Oishi, S., \& Biswas-Diener, R. (2010). New well-being measures: Short scales to assess flourishing and positive and negative feelings. Social Indicators Research, 97, 143-156.

Einarsen, S., Aasland, M.S., \& Skogstad, A. (2007). Destructive leadership behavior: A definition and conceptual model. Leadership Quarterly, 18, 207-216.

Emerson, R.M. (1976). Social exchange theory. Annual Review of Sociology, 2, 335-362.

Hofstede, G. (2007). Asian management in the 21st century. Asia Pacific Journal of Management, 24, 411-420.

Kanungo, R.N. (2001). Ethical values of transactional and transformational leaders. Canadian Journal of Administrative Sciences, 18, 257-265.

Kelley, H.H. (1968). Interpersonal accommodation. American Psychologist, 23, 399-410.

Khan, K., Abbas, M., Gul, A., \& Raja, U. (2015). Organizational justice and job outcomes: Moderating role of Islamic work ethic. Journal of Business Ethics, 126, 235-246.

Kristof, A. L. (1996). Person-organization fit: An integrative review of its conceptualizations, measurement, and implications. Personnel Psychology, 49, 1-49. 
Murtaza, G., Abbas, M., Raja, U., Roques, O., Khalid, A., \& Mushtaq, R. (2016). Impact of Islamic work ethics on organizational citizenship behaviors and knowledge-sharing behaviors. Journal of Business Ethics, 133, 325-333.

Naseer, S., Raja, U., Syed, F., Donia, M., \& Darr, W. (2016). Perils of being in-group of a bad leader: Exploring the combined effects of despotic leadership, leader member exchange, and perceived organizational politics on behaviors. Leadership Quarterly, 27, 14-33.

Ntalianis, F., \& Raja, U. (2002). Influence of religion on citizenship behavior and whistle blowing. Current Topics in Management. 7, 79-98.

Rawwas, M.Y.A., Javed, B., \& Iqbal, M.N. (2018). Perception of politics and job outcomes: moderating role of Islamic work ethic. Personnel Review, 47, 74-94.

Schilling, J. (2009). From ineffectiveness to destruction: A qualitative study on the meaning of negative leadership. Leadership, 5, 102-128.

Schriesheim, C. \& Tsui, A.S. (1980). Development and validation of a short satisfaction instrument for use in survey feedback interventions. Paper presented at the Western Academy of Management Meeting, Phoenix, AZ.

Schyns, B., \& Hansbrough, T. (2010). When leadership goes wrong: Destructive leadership, mistakes, and ethical failures. Charlotte, CT: IAP.

Williams, L. J., \& Anderson, S. E. (1991). Job satisfaction and organizational commitment as predictors of organizational citizenship and in-role behaviors. Journal of Management, 17, 601-617.

Yousef, D. A. (2000). Organizational commitment and job satisfaction as predictors of attitudes toward organizational change in a non-western setting. Human Relations, 53, 513-537. 
Zulfikar, Y. F. (2012). Do Muslims believe more in Protestant work ethic than Christians? Comparison of people with different religious background living in the US. Journal of Business Ethics, 105, 489-502. 
Table 1: Means, Standard Deviations, Correlations, and Reliabilities

\begin{tabular}{|c|c|c|c|c|c|c|c|}
\hline & Mean & $\mathrm{SD}$ & 1 & 2 & 3 & 4 & 5 \\
\hline 1. Despotic leadership & 2.70 & .91 & $(.81)$ & & & & \\
\hline 2. Islamic work ethic & 3.67 & .59 & -.05 & $(.86)$ & & & \\
\hline 3. Job performance & 3.48 & .82 & $-.36 * *$ & $.40 * *$ & $(.88)$ & & \\
\hline 4. Job satisfaction & 3.76 & .77 & $-.15^{*}$ & .01 & .01 & $(.86)$ & \\
\hline 5. Psychological well-being & 5.32 & 1.16 & $-.19 * *$ & $.16 * *$ & $.17 * *$ & $.44 * *$ & $(.90)$ \\
\hline
\end{tabular}




\section{Table 2: Moderated Regression Analysis}

\section{Job Performance Job Satisfaction Psychological Well-Being}

$\begin{array}{lllllll}\beta & \Delta R^{2} & \beta & \Delta R^{2} & \beta & \Delta R^{2}\end{array}$

\section{Step 1}

Gender

$\mathrm{O} 1$

$\mathrm{O} 2$
.12

$-.03$

$-.18^{* *}$

$.07 * * *$

$-.26 * * *$

$-.06$

.1

$-.20 * * *$

.07

$.23 * * *$
$-.16^{*}$

.06

.03

$.03 *$

Step 2

Despotic leadership (DL) $\quad-.36^{* * *}$

Islamic work ethic (IWE)

Step 3

$\mathrm{DL} \times \mathrm{IWE}$

$-.15 * * \quad .02 * *$

$-.18 * *$

$.03 * *$

$-.23 * * *$

$-.18 * *$

$.20 * *$

$-.07 * * *$

Notes: $\mathrm{N}=303$. Gender was assessed with one dummy variable ( $1=$ male; $2=$ female); organization was assessed with two dummy variables $(\mathrm{O} 1=$ high school; $\mathrm{O} 2=$ bank $)$

$* p<.05$.

$* * p<.01$.

$* * * p<.001$. 
Figure 1

Interactive Effect of Despotic Leadership and Islamic Work Ethic on Job Performance

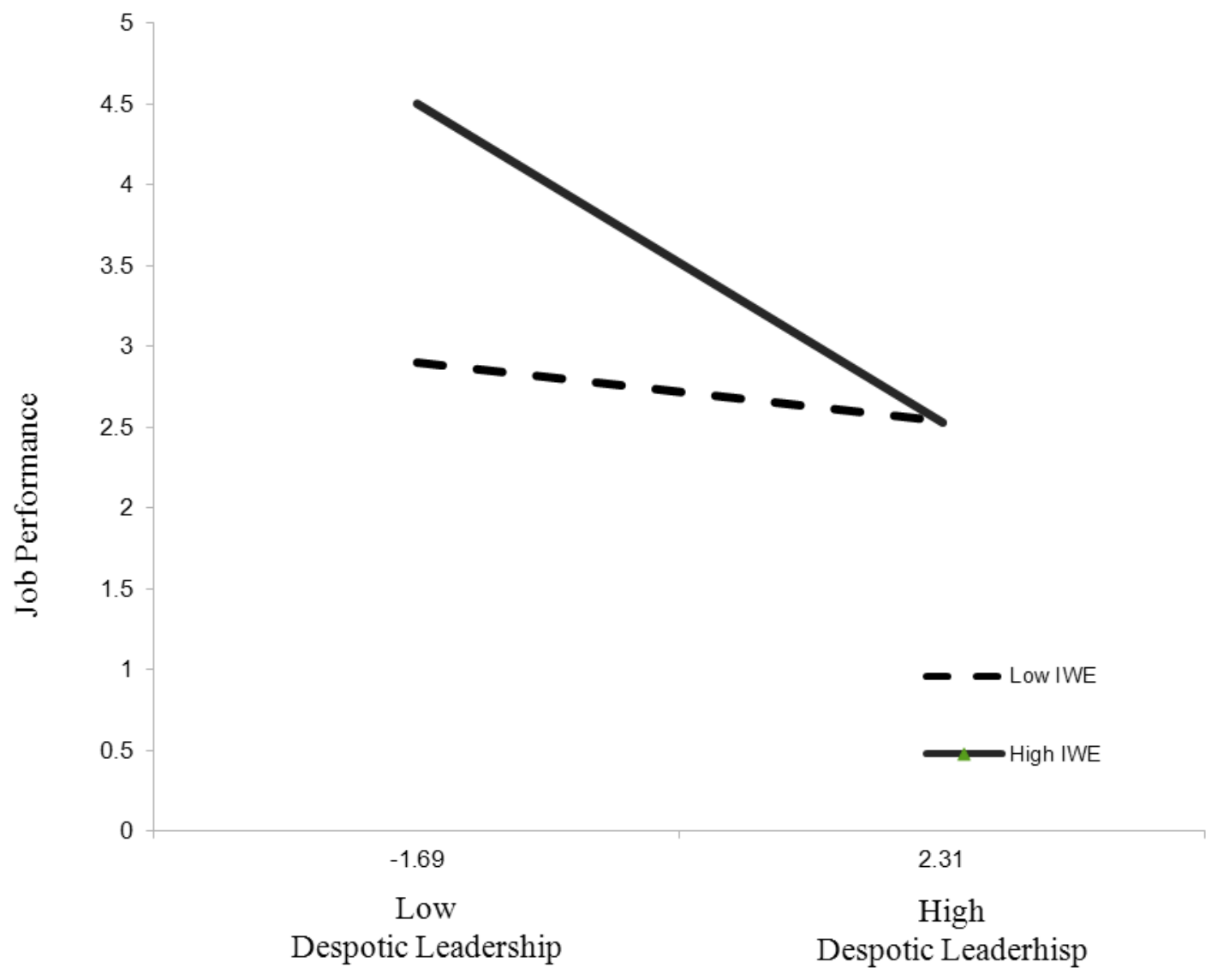


Figure 2

Interactive Effect of Despotic Leadership and Islamic Work Ethic on Job Satisfaction

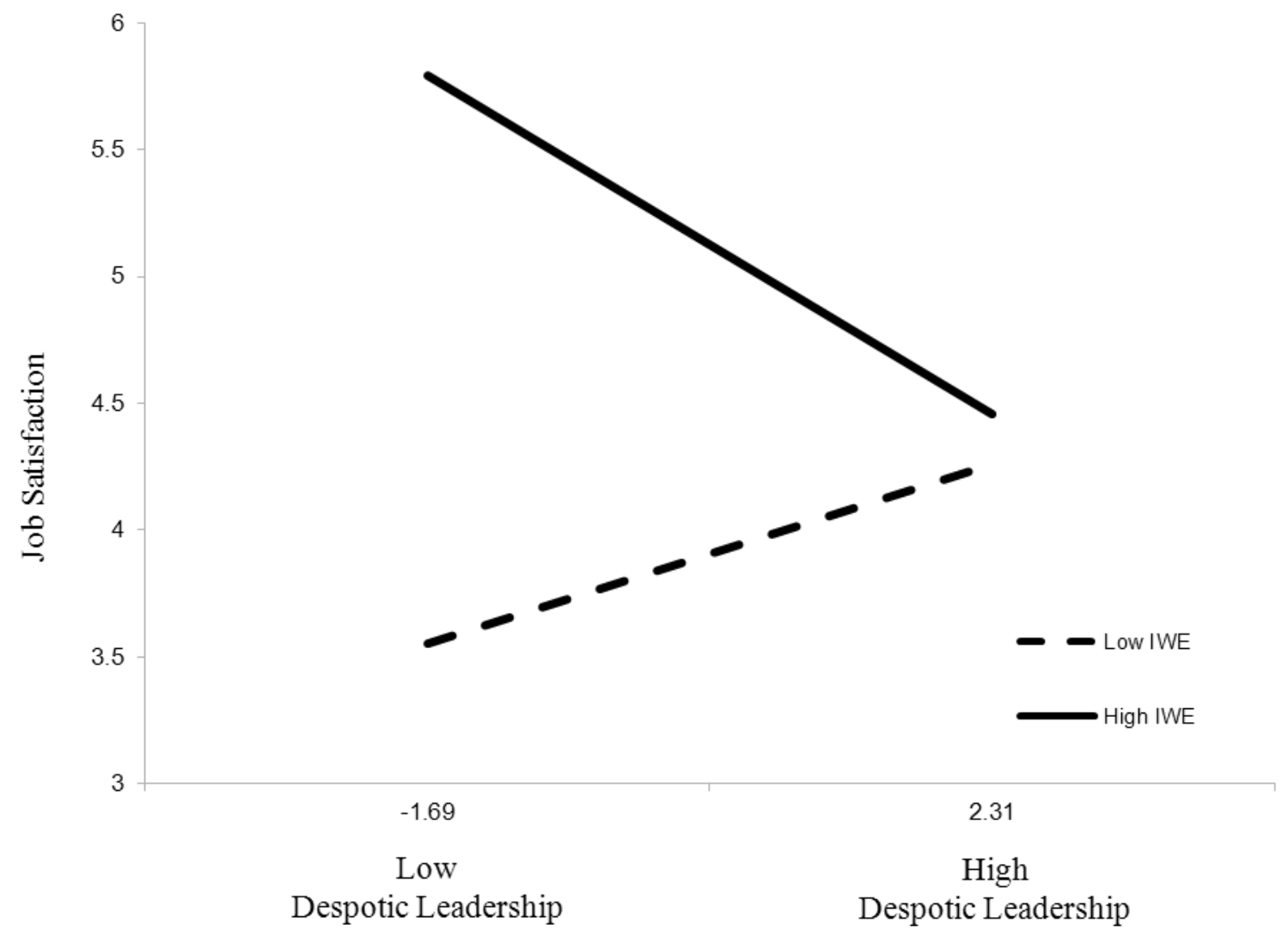


Figure 3

Interactive Effect of Despotic Leadership and Islamic Work Ethic on Psychological WellBeing

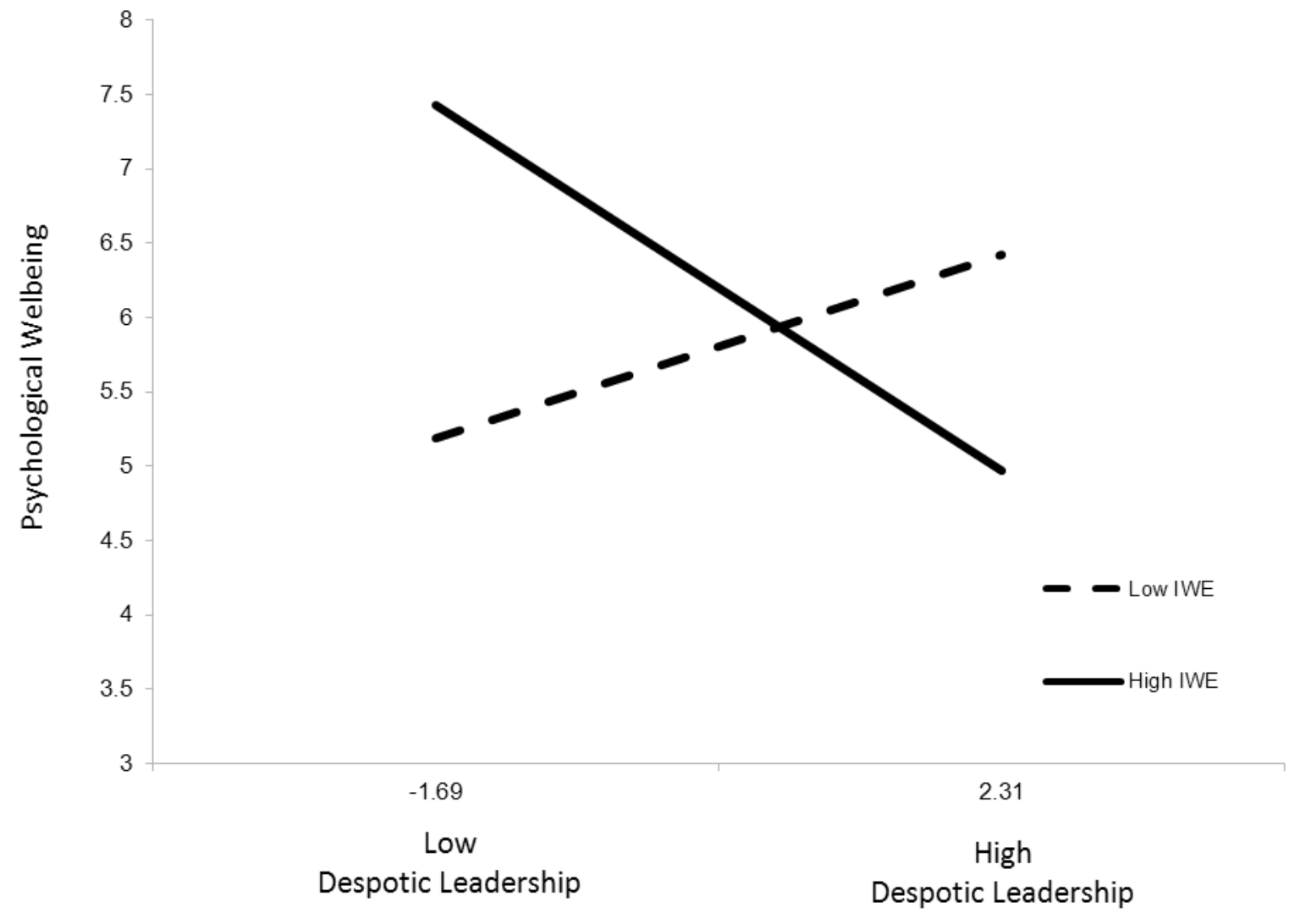

